\title{
Study of Bending Strength and Numerical Modeling of Wooden and Plywood Frame Elements
}

\author{
T. Akgul*, A.C. Apay, E. Aydin, Y. Sumer \\ Department of Civil Engineering Technology Faculty, Sakarya University, Sakarya, Turkey
}

\begin{abstract}
Modern Frame Systems have appeared by development of frame systems due to search for optimum cost and quality of construction, along with the increased number of multi-storey concrete construction today. Although the initial investment costs of the modern frame systems are high, there use has increased 50-100 times with respect to the traditional methods. With the modern frames, reduction or complete elimination of extra operations, such as cutting and sizing on site, have led to savings on workmanship and time. These systems aim at providing wide range of application in a short time by using minimum workmanship and, consequently, maximum number of application. This study explores, experimentally and numerically, the bending strength of wooden and plywood panels most frequently used for the construction today.
\end{abstract}

DOI: 10.12693/APhysPolA.127.1414

PACS: 81

\section{Introduction}

Frames, usually called as classical or traditional frames, made entirely of wooden raw material, are suffering increased loss every day. These building elements constitute a system, in which lumber is the basic material, from the pillars to the surface elements. As these frame systems are based on more material and workmanship, their costs are high. Wooden forms are materials which are used in place several times, and are subsequently discarded and used as fuel. Switching to mass production of the forms, thanks to the advanced technology, made it possible to produce the forms from larger panels, has ensured mechanical set-up and increased the production quantities [1]. As a result of technological advance, big firms were established, particularly in 1970s, and production of construction materials, tools and instruments has become widespread at a fast pace. During this period, the increased population and, consequently, housing requirements in Turkey have caused widespread use of modern frame technologies [2]. Frames account for about $40-60 \%$ of framed buildings. Furthermore, the frame cost accounts for around $10 \%$ of all construction costs [3]. Moreover, share of frame workmanship in this cost is three times the cost of the frame material. For this reason, it would be more efficient to reduce cost of the frame workmanship, rather than the cost of the frame itself. For this reason, development of practical joining details, without the need of nailing the forms together each time and reusing them many times, have made the modern mold techniques more advantageous in terms of savings on time and workmanship [4]. In the production of frame, the frame surface components, which are among the main elements of the frame and give shape to the concrete, are manufactured from different materials. This study compares bending strengths of the wooden

* corresponding author; e-mail: tahirakgul@sakarya.edu.tr and plywood panels which are widely used nowadays.

\section{Material and method}

The methodology of the research consists of making laboratory studies with different types of frame elements and developing an appropriate finite element modeling approach to shed light on future studies.

\subsection{Wooden panels}

Wood is the most widely used material for manufacturing of traditional reinforced concrete frames. It is preferred as it has a much lower investment cost, than the fabricated products; does not require quality workmanship and is amply available in all areas. These forms are made at the construction site to the sizes of the related construction element, and are consisting of frame surfaces and ancillary elements [5]. After hardening of the concrete, the forms are disassembled into parts. In this system, where the primary material is solely the solid wood, waste of material and workmanship is high. It is most unlikely to reuse the frames. In this system, the frame parts giving the desired form to the concrete are installed by cutting and nailing them individually on site in accordance with the sizes specified in the project. Framemaking time is long.

\subsection{Plywood sheets}

Plywood, of north-european origin, is a film-coated plywood with a flexible character. Production of plywood starts by stripping the logs to form plies. And then the plies are adhered to each other, with the ply fibers oriented perpendicularly for making use of the natural durability of the wood grains. For adherence of the plies, phenolatic formaldehyde resin is used. Edges of the plywood are coated by acrylic latex paint [6]. Number of use is 15 times, when the frame surface is not coated by a protective coat and up to 60 times, when it is coated. Number of use also varies depending upon the wood material the plywood is made of. Although those in the thickness range of 9-21 $\mathrm{mm}$ are generally preferred, the production is made in range of $4-50 \mathrm{~mm}$ in thickness. As 
plywood is a lightweight material, it is possible to work with large sheets. It provides advantage for construction sites where no crane is used. Plywood surface is also convenient for cold weather with its insulating nature, with respect to the heat energy emitted by the concrete during setting. As plywood sheets are inserted into the concrete frame in case of modular frame sheets, they are resistant against wear and have a long service life. They are also cost-effective, as they may be used as many times by reversing them after a certain number of uses [7].

\subsection{Three-point bending test}

In this study, bending strength tests were performed on the test samples produced from the frame surface materials mentioned above. A sample group of wood and plywood was prepared. Thickness of all samples is selected as $18 \mathrm{~mm}$. Each group contains 3 test samples. The prepared sample groups include (i) wood frame material $(18 \mathrm{~mm})$ and (ii) plywood frame material $(18 \mathrm{~mm})$.

Frame samples used in the bending tests have crosssection of $18 \times 100 \mathrm{~mm}$ and are $500 \mathrm{~mm}$ in length. The samples were kept subject to three-point bending test in accordance with the standards [8]. Figure 1 shows geometry and loading status of the test setup.

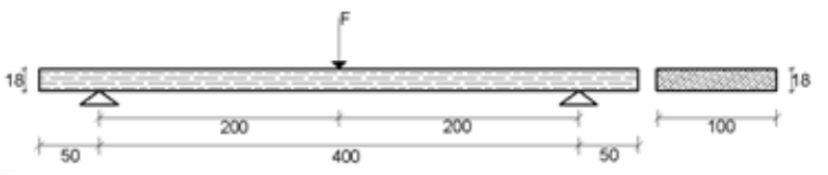

Fig. 1. Loading status of the bending test.

\section{Numerical modeling}

Characterization of the solid pine wood and plywood frame materials, which have been numerically modeled [9].

\subsection{Wood}

Material feature of the wood, an orthotropic material, is characterized by use of a matrix consisting of 9 rigidity terms related to modulus of elasticity, shear modulus and Poisson's ratio. All these terms are described in line with three prime axes (Fig. 2). Boundary conditions on the beam models have been generated as fixed at one edge and with roller support on the other edge in accordance with the test set-up, without use of symmetry feature. Typical finite element mesh used during these simulations has been chosen, according to the similar studies conducted in the literature. In the finite elements model, the wooden element is represented by solid elements with 3 dimensions which have 8 nodal points and uses reduced integration formulation (C3D8R). Compared to normal elements, the reduced integration elements provide solution at fewer integration points and increase the solution time of the computer.

In the numerical model consisting of three-dimensional solid elements, the mechanical characteristics of the solid wood pine element are given in Table I.

Rigidity values $\left(D_{i j k l}\right)$ obtained by using mechanical characteristics of Table I are given in Table II.
Mechanical properties of the timber.

TABLE I

\begin{tabular}{c|c|c|c|c|c|c|c}
\hline \hline$E_{1}$ & $E_{2}$ & $E_{3}$ & $G_{12}$ & $G_{13}=$ & $v_{12}=$ & $v_{13}=$ & $v_{23}=$ \\
$v_{32}$ \\
{$\left[\mathrm{~N} / \mathrm{mm}^{2}\right]$} & $E_{2}$ & $E_{3}$ & {$\left[\mathrm{~N} / \mathrm{mm}^{2}\right]$} & $G_{23}$ & $v_{21}$ & $v_{31}$ & $v_{32}$ \\
\hline 900 & 500 & 12000 & 40 & 700 & 0.558 & 0.038 & 0.015
\end{tabular}

Rigidity terms obtained for the solid pine

TABLE II element used in the tests.

\begin{tabular}{c|c|c|c|c|c|c|c|c}
\hline \hline$D_{1111}$ & $D_{2222}$ & $D_{3333}$ & $D_{1122}$ & $D_{1133}$ & $D_{2233}$ & $D_{1212}$ & $D_{1313}$ & $D_{2323}$ \\
\hline 1311.1 & 727.5 & 12040.3 & 732.5 & 60.81 & 26.38 & 40 & 700 & 700
\end{tabular}

\subsection{Plywood}

Plywood is a panel consisting of an odd-number (varying between 3 and 21) of wood layers. Fiber directions on the overlapping layers are perpendicular to each other. Wood layers are pressed together using glue, under high pressure, to obtain plywood element. There are plywood elements in the market that are obtained from different types of wood. In this study, bending test has been modeled for 11-layered plywood element obtained from the birch (Modulus of elasticity $8825 \mathrm{MPa}$ ). In the finite elements model, the plywood has been modeled as isotropic solid element with 8 nodal points using reduced integration formulation (C3D8R). Glue materials have been modeled by cohesive elements (COH3D8), again threedimensional, with thickness of $0.1 \mathrm{~mm}$. For definition of two layers making a $90^{\circ}$ angle to each other, the material orientation was defined as perpendicular to the wood elements (Fig. 3). Interaction between the plywood and the adhesive has been achieved by characteristic of "surface tie". Load has been applied to the center nodal points of the beams with displacement control. For definition of the material characteristic of the plywood, the experimental data obtained from the tensile stress and compression tests performed by Chua for plywood [10] were used. In this study, material properties were defined for plywood in finite element's elastic modulus: $8000 \mathrm{~N} / \mathrm{mm}^{2}$, Poisson's ratio: 0.3 , yield strength: $15.58 \mathrm{~N} / \mathrm{mm}^{2}$.

The constitutive response of cohesive elements is determined by traction-separation relationship (ABAQUS). The separation in cohesive elements is defined as relative displacement of upper nodes with respect to lower nodes [12]. The accepted properties of cohesive elements from the literature are given in Table III, where $K_{n}$ and $K_{s, t}$ are the stiffness components in normal and shear directions of element. $\sigma_{c}^{\lim }$ and $\tau_{c}^{\lim }$ are peeling and shear strengths of the cohesive elements and $\sigma_{c}^{c r}$ is the critical fracture energy of glue material.

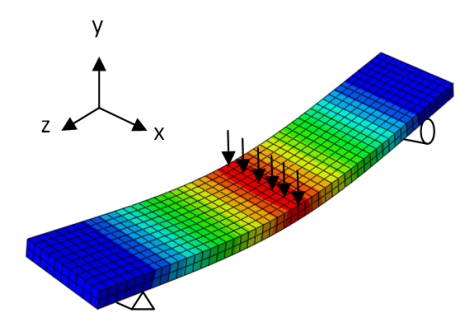

Fig. 2. Prime axes of the wood element. 


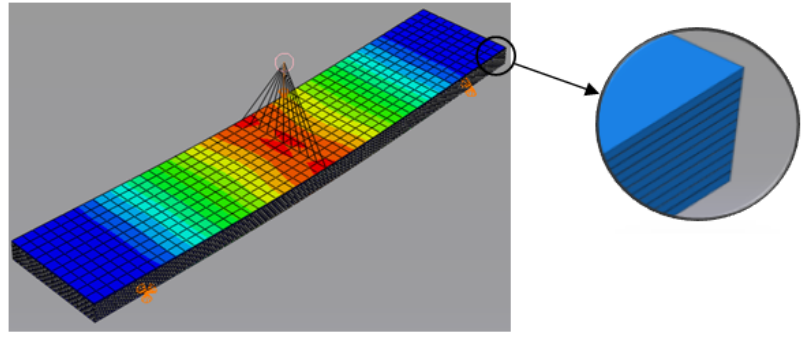

Fig. 3. Appearance of plywood numerical model.

Cohesive element properties. TABLE III

\begin{tabular}{c|c|c|c|c}
\hline \hline $\begin{array}{c}\mathrm{K}_{n} \\
{[\mathrm{MPa}]}\end{array}$ & $\begin{array}{c}\mathrm{K}_{s, t} \\
{[\mathrm{MPa}]}\end{array}$ & $\begin{array}{c}\sigma_{c}^{\lim } \\
{[\mathrm{MPa}]}\end{array}$ & $\begin{array}{c}\tau_{c}^{\lim } \\
{[\mathrm{MPa}]}\end{array}$ & $\begin{array}{c}\sigma_{c}^{c r} \\
{[\mathrm{~N} / \mathrm{mm}]}\end{array}$ \\
\hline 1910 & 250 & 20 & 6.89 & 0.6
\end{tabular}

\section{Findings}

Load displacement graphs obtained from the performed test and numerical analysis are shown in Fig. 4a for the wood element and in Fig. 4b for the plywood element.
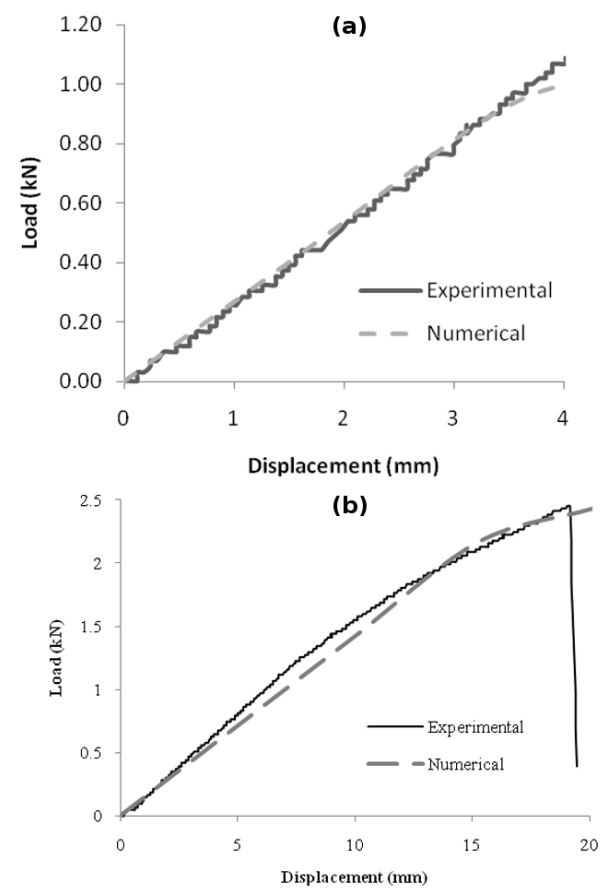

Fig. 4. Comparison of experimental and numerical results (a) the wood element, (b) the plywood element.

When the bending test graphs are examined, it is seen that numerical results agree well with those obtained from the experimental results and finite element model captures the maximum deflection with acceptable accuracy.

\section{Conclusion and assessment}

In the performed experimental studies, the mechanical properties of different types of frame surface components used at construction site were determined and compared with each other to find the advantages and disadvantages of each other.

- As a result of the test, the frame material with the highest tensile stress has turned out to be wood. The reason is that wood is a construction material having natural fibers. When stress tests were applied to the wood samples, application of load in parallel with fiber directions has caused appearance of high tensile stress. However, as the wood frame material cannot be used many times, requires workmanship and uses wood as raw material, it is not considered proper to use it in collective housing and contracting works.

- With the second part of the study, refined 3D finite element modeling procedure has been described in detail and the proposed modeling procedures have been shown to efficiently estimate the loaddeflection behavior through comparisons between experimental and finite element result. With the three-dimensional numerical models developed, the bending behavior of both frame elements was estimated accurately and thus can be used for further investigations.

\section{References}

[1] A.S. Hanna, Concrete formwork systems, Marcel Dekker, New York 1999.

[2] M. Altan, Betonarme elemanlarda kalıp, I.T.U. Civil Engineering Faculty Press, İstanbul 1992.

[3] G. Kürklü, H. Akbulut, Tüm yönleriyle beton ve betonarme kalıpları, Teknik Publishing House, Ankara 2004.

[4] N. Benli, Master Thesis, Çok katlı yüksek yapılarda kullanılan kalıp sistemlerinin irdelenmesi, Dokuz Eylül Uni, İzmir 2005.

[5] A.C. Apay, T. Akgül, E. Şahin, J. Energ. Edu. Sci. Technol. A 28, 591 (2012).

[6] Teknik-El, Teknik-el Kalip Sistemleri, http://www. teknik-el.com, 2005.

[7] MESA, Mesa Manufacturing Industry Presentation Catalog, Ankara 2005.

[8] E. Sahin, Master Thesis, İşaat kalıp malzemelerinin fiziksel ve mekaniksel özelliklerinin araştırılması, Sakarya University, Sakarya 2010.

[9] Abaqus, User's Manual, Version 6.9., Hibbit, Karlsson $\& 3$ Sorensen, Inc. Pawtucket Rhode Island, USA 2009.

[10] L.C. Ann, Finite element analysis of single skin plywood steel deck dry floor system, Univ. of Technology, Malaysia 2009.

[11] B. Faggiano, A. Marzo, A. Formisano, F.M. Mazzolani, Comput. Struct. 87, 1 (2009).

[12] I.V. Ivanov, T. Sadowski, Comp. Mater. Sci. 45, 729 (2009). 